\title{
Decoupled Power Flow Of A Single Stage Grid Connected PV System With Multilevel Inverter
}

\author{
Umesh Kumar Sinha
}

\begin{abstract}
With the wide installation of solar PV array in respect of other renewable power generation, there is a scope of feeding the surplus power to grid for better and economic power utilization. This paper presents an independent control of active and reactive power flow of single stage grid connected PV system with multilevel inverter. Vector control scheme has been implemented in $d-q$ reference frame which is synchronously rotating with the grid frequency. Two current control loop has been used, one for $d$-axis and other for $q$-axis to control the current injected into the grid such that it has low total harmonic distortion and in phase with the grid voltage. In addition to that, a DC voltage control loop has also been implemented to operate the inverter at the desired DC link voltage that is the DC voltage corresponding to maximum power, which is obtained by the MPPT algorithm. Grid-connected inverters have wide application in the field of distributed generation and power quality. The above scheme employs a three-phase three-level Diode clamped multilevel inverter to improve the current injected to grid.
\end{abstract}

Index Terms - PV Array, Renewable Power Generation, Active and reactive power, Multilevel inverter, Vector control, d-q reference frame, grid frequency, MPPT algorithm, Grid connected inverter, three-phase three-level diode clamped multilevel inverter.

\section{INTRODUCTION}

From last two decades the technology in the field of power generation is searching for a quality power with environmentally friendly nature. This lead to a phenomenal change in the way power is generated and utilized. The grid can act as a source as well as a sink for any amount of power. The use of grid connected inverters is on the increase both at the point of generation and utilization[1]. On the generation end they are used to integrate renewable sources of power with the ac grid. On the utility end they are used in power factor correction, mitigation of harmonics drawn from the grid and to improve the quality of voltage at the load terminals. In all the above applications, it must have been insured that the switching frequency ripple injected in to the grid by the grid-connected inverter is within the limits specified by the grid standards. Further the grid-connected inverter is expected to witness common grid disturbances like voltage sags, voltage swells [2]. These disturbances are expected to be controlled by the grid-connected inverters with good control performance. Also, with development in the semiconductor devices like IGBT, SCR, Power MOSFET the required power handling capabilities of the grid-connected inverters have increased to MWs in the present day. So the control of active and reactive power is also another important topic to be handled in grid connected PV system. Thus, in this project PWM based multilevel

Umesh Kumar Sinha, Associate Professor, National institute of Technology, Jamshedpur-831014 (India) voltage source inverter has been used which will perform this mode that is forward blocking, forward conducting and reverse conducting. In order to have output parameters in specified values the input to the DC link capacitor should be fixed and correspond to the maximum power point voltage. This can be done by implementing the maximum power point tracking algorithm to a Single stage grid connected inverter or two stage grid connected inverter.

\section{SINGLE STAGE AND TWO STAGE GRID CONNECTED PV SYSTEM}

Based on the number of stages, they can be classified as two stage system and single stage system. In two stage system, the initial block constitutes DC-DC converter that is boost or buck-boost converter, which is used for Maximum Power Point Tracking (MPPT) and boosting the PV voltage (if necessary). The next block consists of the inverter (DC-AC) that inverts the first block DC output to $\mathrm{AC}$ at grid frequency. The major drawbacks of this system are less efficiency and high cost because of the greater number of intermediate stages from the PV array to the grid. Single stage system, the inverter block is integrated with all the control like MMPT and grid current and voltage control inversion, boosting (if necessary) and synchronization to the grid are taken care of by the inverter itself. As only one stage is used for processing the DC power to convert it into AC, this type of systems is more efficient and less costly than two stage systems. But the use of a single stage PV system during off peak periods of the sun is very difficult because of the lack of boosting capability as compared to that of a two-stage grid connected solar PV system.

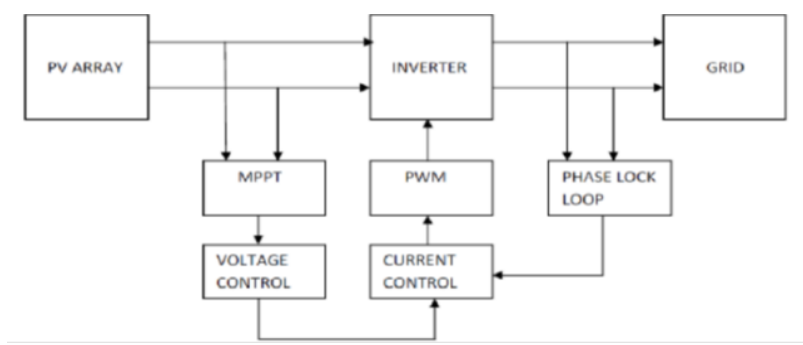

Figure 1 single stage grid connected PV system

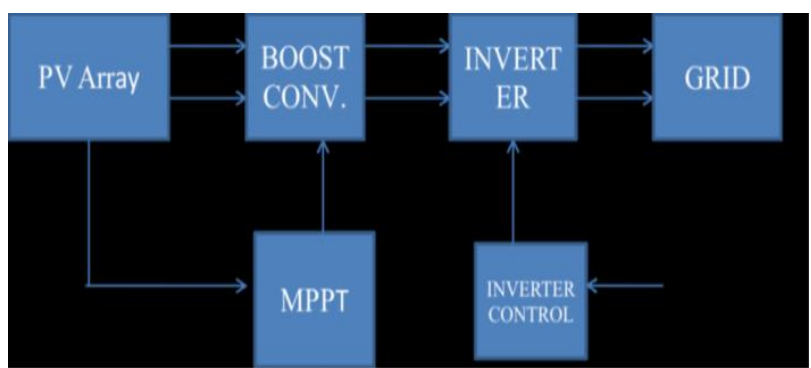

Figure 2 Two stage grid connected PV system 


\subsection{Control Scheme}

\subsubsection{MPPT}

The basic idea of the MPPT scheme is to harvest the maximum power from the PV array. That is to obtain the DC voltage correspond to the maximum power [6]. These DC voltages corresponding to the maximum power will be the input to the converter so the voltage control loop reference will be determined by the MPPT scheme. As it is a single stage solar PV system the maximum power point can be done by implementing a DC voltage control loop.

\subsubsection{Grid synchronization with PLL}

The Phase Locked Loop (PLL) is basically used to match a local signal phase with the input phase. In a 3-phase grid system, the PLL is used to synchronize the output of the grid-connected converter with the grid. PLL provides information on the frequency, phase and amplitude of the grid voltage. PLL is necessary in grid-connected power converters for their closed loop monitoring and control [5]. The unit vectors generated by the PLL are used for reference signal generation for closed loop rotating reference frame control of grid connected inverter

\subsubsection{Current control}

The grid variables that are the three-phase currents and voltages are transformed in to synchronously rotating reference frame using the co-ordinate transformation techniques. Two control loops are implemented one for the direct-axis and another one for the quadrature-axis. The proposed scheme aims at achieving balanced currents even during unbalanced voltage dips.

\subsubsection{Voltage control}

A fixed DC bus voltage is required in grid-connected inverters. Usually, a DC bus voltage control loop is used to ensure this. In a grid connected solar PV system usually this voltage is the DC voltage at maximum power. For a two-level three-phase inverter topology with three-wire configuration, the DC bus voltage control is usually simple. However, in MLI topologies the issue of balancing the individual DC bus capacitor voltages needs attention. This DC link capacitor voltage deviation problem can be resolved either by using additional auxiliary circuits or by means of adopting proper switching sequence by a suitable PWM scheme. This paper presented a general view of actual solutions for applications of the PV energy systems [1]. The paper covers some important issues such as the most reliable models used for simulation that are useful in the design of control systems, and the maximum power point tracking function, especially in distributed applications. This work proposes an advanced control of power converters used in photovoltaic solar energy. The boost converter and NPC three-level inverter are usually associated with photovoltaic cells [2]. A maximum power point tracking algorithm is adopted in this case to maximize the output power by using the sliding mode control approach. In this paper two novel carrier-based multilevel PWM schemes are presented which help to optimize or balance the switch utilization in multilevel inverters [3]. An analysis of how existing multilevel carrier-based PWM affects switch utilization for the different levels of a neutral point clamped inverter is also explained. This paper proposes a unique carrier-based pulse width modulation (CBPWM) strategy [4] for a three-level neutral-point-clamped inverter that works satisfactorily and with uniform convergence time over the full power factor (PF) range of the load variation. There are several ways of implementing voltage balance in multilevel converters [5]. This paper presents (1) diode-clamp, (2) flying-capacitors, and cascaded-inverters with separate DC sources. The operating principle, features, constraints, and potential applications of these converters are discussed.. Second harmonic power oscillations seen in typical cascaded topologies can also be eliminated or reduced through use of the proposed topology [6]. This paper also discusses about comparative analysis of extended $\mathrm{P} \& \mathrm{O}$ algorithm and conventional $\mathrm{P} \& \mathrm{O}$ algorithm [7]. The generation of the orthogonal voltages system an evaluation of the most employed techniques is shown: Transport Delay, Inverse Park Transformation, Hilbert Transformation [8]. In this paper, an implementation of the control and the synchronization algorithms for a Voltage Source Inverter used in a grid-connected structure [9] is carried out. The aim is to control power factor at grid, to feed power into the grid, and to decrease phase current distortion of VSI. The design includes `binary', 'trinary' and 'modified multilevel connection' (MMC)-based topologies suitable for varying input sources from solar photo-voltaics (PV) [10]. Three levels inverter, six-command strategies are applied in order to compare their performances. The Total Harmonic Distortion (THD) [11], is evaluated for various modulation index. Controller design for six-switch pulse width-modulated (PWM) voltage source rectifiers (VSRs) [12], is often accomplished in the rotating $\mathrm{d}-\mathrm{q}$ frame coordinates in order to achieve a high-performance control. In this paper a three-phase, DC/AC converter suitable for distributed power applications [13], is proposed. This paper presents a three-phase grid-connected photovoltaic generation system with unity power factor for any situation of solar radiation [14]. The model of the PWM inverter and a control strategy using $\mathrm{dq} 0$ transformation are proposed the system operates as an active filter capable of compensate harmonic components and reactive power, generated by the other loads connected to the system.

\subsection{Maximum power point tracking}

Maximum power point tracking (MPPT) techniques are used in PV systems to maximize the PV array output power by constantly tracking the maximum power point (MPPT), which is influenced by the panel's temperature and on irradiance conditions. Among many types of tracking methods, we have used incremental conductance method to track the MPPT of this PV array. For the model shown below the PV array has 29 series modules per string, at irradiance $1000 \mathrm{~W} / \mathrm{m} 2$ and temperature $25 \mathrm{deg}$., the MPP voltage is $29 \mathrm{~V}$ for a module.

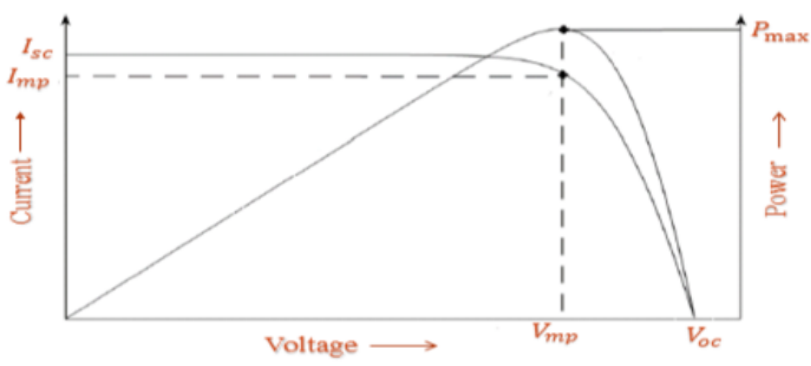

Figure3 Characteristic of PV panel

\subsubsection{PERTURB AND OBSERVE METHOD}

It is most common method of maximum power tracking algorithm and it is also easy to implement. It is based on the principle that the working voltage of the PV array is 
perturbed in a known direction and if the power drained from the PV array increases, this means operating point is approaches toward the MPP and therefore, the working voltage must be further perturbed in the similar direction. Otherwise, if the power obtained from the PV array decreases, the operating point has gone away from the MPP and, thus, the direction of the perturbing voltage has to be overturned as shown in Figure7. In other words, the algorithms is based on the fact that, with the change in voltage if the change in power goes towards its maximum point then the perturbation of voltage is carried out in the same direction till the power comes in a band of its maximum limit. The main advantage of Perturb and Observe method is the simplicity of implementation but the main drawback of this algorithm is the oscillations of the operating point around the maximum power point.

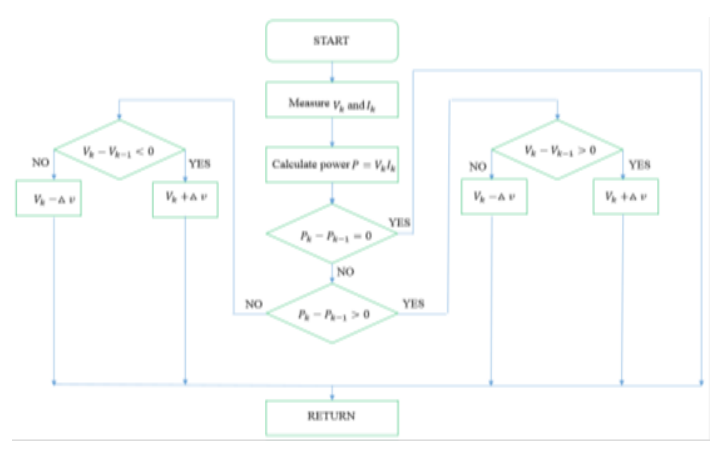

Figure 4 P\&O algorithm of MPPT

\subsubsection{INCREMENTAL CONDUCTANCE METHOD}

The disadvantage of perturb and observe method to track the peak power under fast varying atmospheric condition is overcome by IC method. The IC can determine that the MPPT has reached the MPP and stop perturbing the operating point. This relationship is derived from the fact that $\mathrm{dP} / \mathrm{dV}$ is negative when the MPPT is to the right of the this method the peak power of the module lies at above $98 \%$ of its incremental conductance.

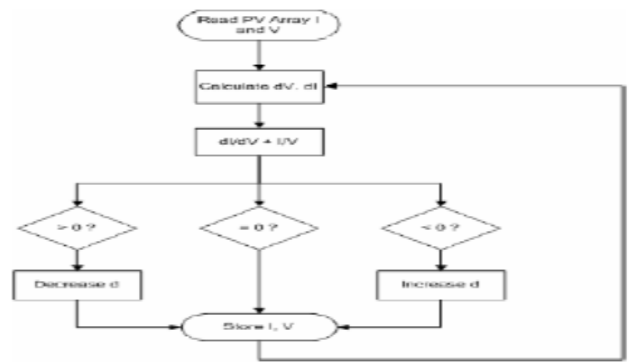

Figure 5 Power versus Voltage graph for IC Algorithm

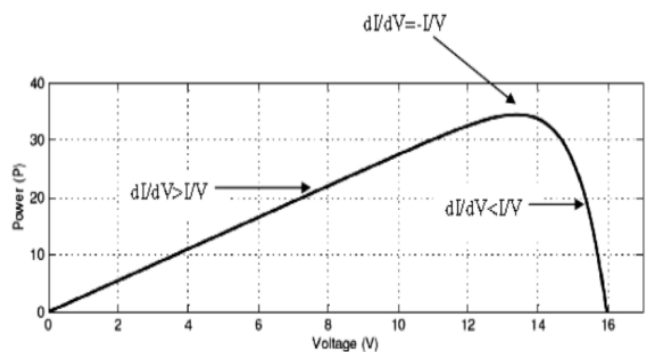

Figure 6 Power versus Voltage graph for IC Algorithm

\section{MATLAB SIMULINK MODELS}

For the model shown below the PV array has 29 series modules per string, at irradiance $1000 \mathrm{~W} / \mathrm{m} 2$ and temperature 25 deg., the MPP voltage is $29 \mathrm{~V}$ for a module [10, 11]. Among many types of tracking methods, we have used incremental conductance method to track the MPPT of this PV array.
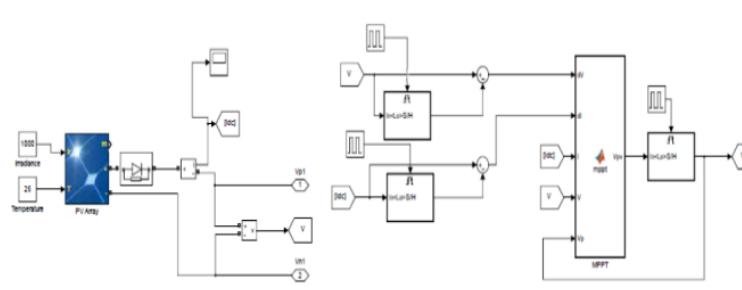

Figure 7 Matlab simulink compact model of MPPT PV panel.

\section{SIMULATION RESULTS}

The proposed control scheme along with a three-phase three-level NPC inverter implemented in MATLAB/Simulink to demonstrate the effectiveness of the proposed vector control scheme for the decoupled control of active and reactive power flow scheme from the inverter to the grid.

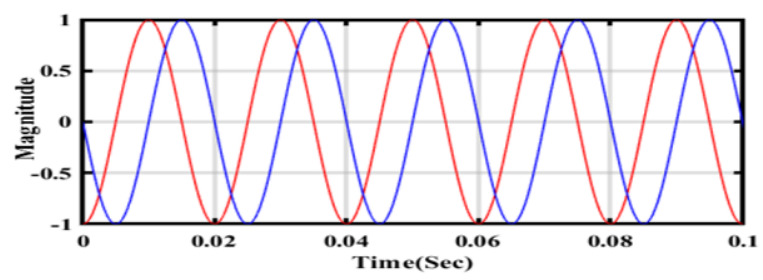

Figure 8 Unit vector generation

The unit vectors generated by the PLL are used for the transformation of feedback variables to different reference frames. Two current control loops are implemented in the dq-reference frame for the direct and quadrature axis. A reference of -5 has set for the quadrature-axis current control loop and a reference of zero has set for the direct-axis current control loop for unity power factor operation. This ensures the independent control of active and reactive power to the grid. The grid current feedback for quadrature-axis shown in Figure 9 and for direct-axis is shown in Figure 10.

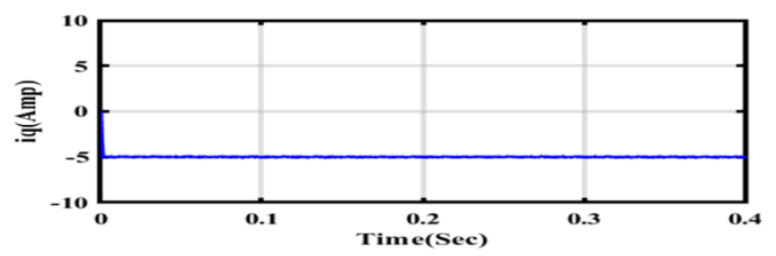

Figure 9 Quadrature axis grid current at Iq ref $=-5$

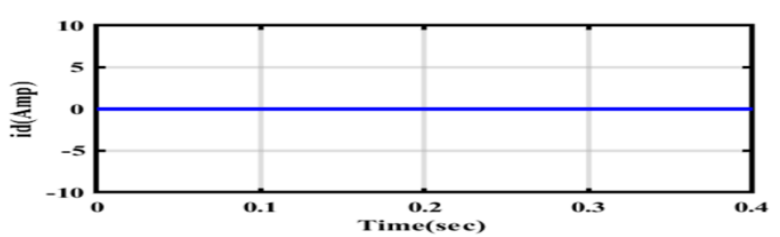

Figure 10 Direct axis grid current at Idref $=0$ 
The simulation result in Figure 11 shows the I-V characteristic \& the P-V characteristic for the PV cell.

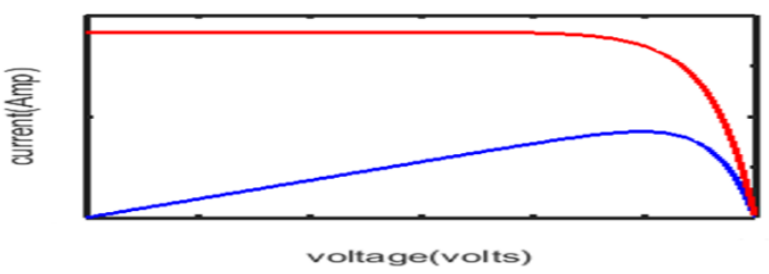

Figure 11 Characteristic of PV panel

In each solar cell there is a point where it can produce maximum power and MPPT utilizes several methods to extract that point. Maximum power point tracking (MPPT) techniques are used in PV systems to maximize the PV array output power by constantly tracking the maximum power point (MPPT), which is influenced by the panel's temperature and on irradiance conditions.

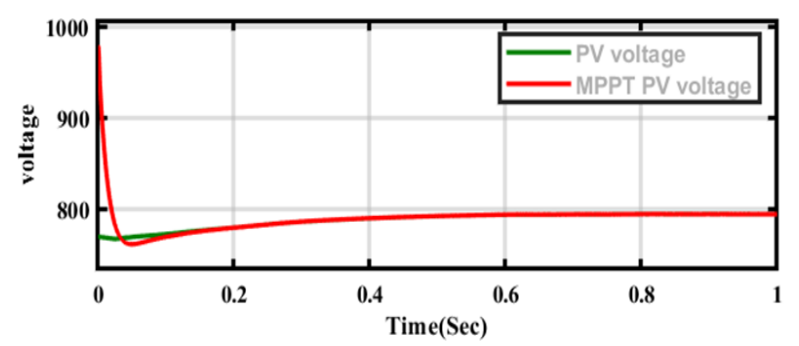

Figure 12 Matlab simulation graph of MPPT

From the above simulation results it can be concluded that the designed controller is giving satisfactory results, because the feedback grid current in the synchronously rotating reference frame is following the references set for the current control loops. The active power transfer to the grid at Iqref $=-5$ and Idref $=0$ with DC link voltage of $300 \mathrm{~V}$ is shown in Figure 13, whereas the reactive power is shown in Figure 14.

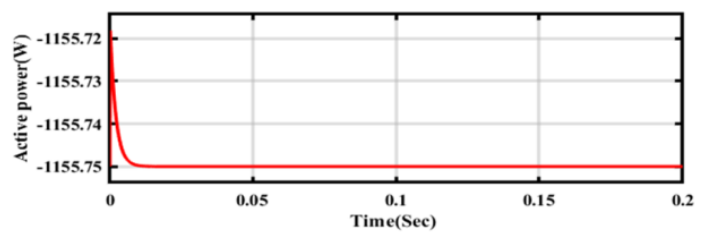

Figure 13 Active power at Id ref $=0$ and Iq ref $=-5$ with $\mathrm{Vdc}=300$

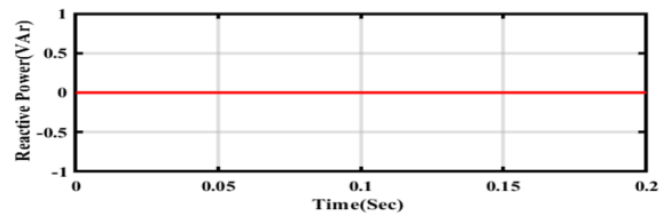

Figure 14Reactive power at Id ref $=0$ and

Iq ref $=\_5$ with $\mathrm{Vdc}=300$

From the above simulation results it can be concluded that the active power and the reactive power can be controlled independently by setting the respective references for the active and reactive current control loops in the synchronously rotating reference frame with unity power factor. The output voltages and the line currents are shown in Figure 15 and Figure 16.

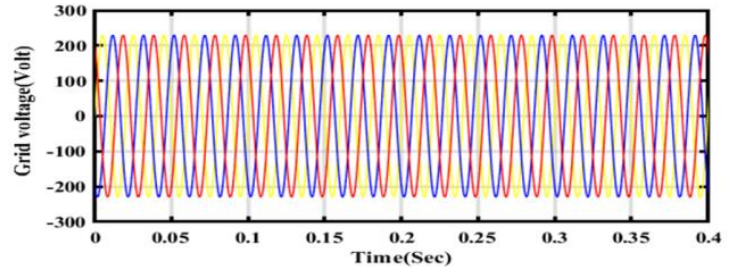

Figure 15 Grid voltage at Id ref $=0$ and Iq ref $=-5$ with $\mathrm{Vdc}=300$

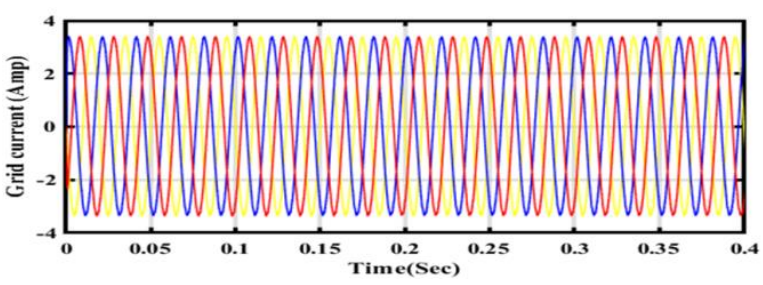

Figure 16 Grid current at Id ref $=0$ and Iq ref=-

$$
5 \text { with } \mathrm{Vdc}=300
$$

The THD analysis of the line current is shown in Figure 40, which gives satisfactory results. All this simulation results verify the effectiveness of the proposed control scheme.

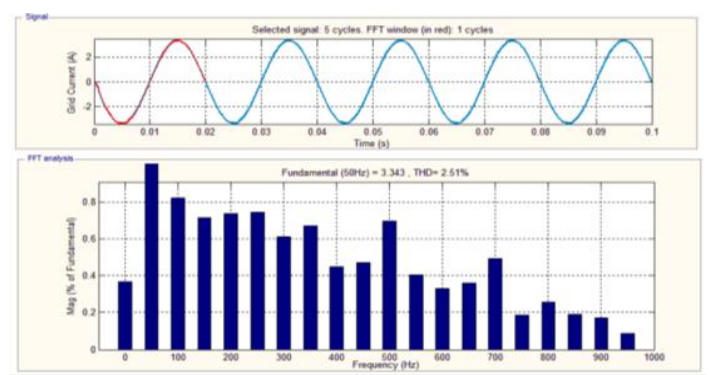

Figure 17 THD analysisat Id ref $=0$ and

Iq ref $=-5$ with $\mathrm{Vdc}=300$

All the relations and equations obtained in previously have been implemented in MATLAB Simulink. A three-level NPC inverter is modelled using Simscape toolbox of MATLAB and the pulses to the switches are generated by using SPWM and SVPWM to analyze the neural point voltage deviation in the grid-connected mode with a total DC link voltage of $600 \mathrm{~V}$.The switching frequency is $10 \mathrm{Khz}$ and at each phase an inductance of $30 \mathrm{mH}$ is used as filter. From the simulation results it can be concluded that the DC link capacitor voltages of a Neutral Point Clamped inverter can be balanced with the proposed space vector pulse width modulation technique without using any additional auxiliary circuits. The simulation results for DC link capacitor voltages with SPWM is shown in Figure 18 and the balanced DC link capacitor voltages after implementing the SVPWM is shown in Figure 19.

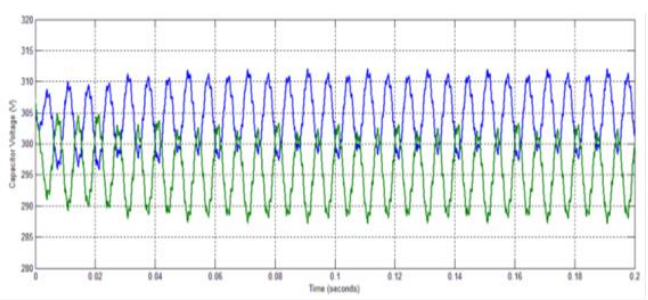

Figure 18 DC link Capacitor voltages with SPWM 


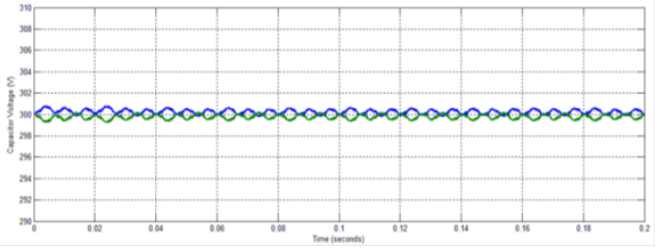

Figure 19 DC link Capacitor voltages with SVPWM

\section{CONCLUSIOSN}

- The proposed control scheme along with a three-phase three-level Diode clamped inverter implemented in MATLAB/Simulink to evidence the effectiveness of the used vector control scheme for the decoupled control of active and reactive power flow scheme from the invert end to the grid end.

- From the above simulation results, it can be concluded that the designed controller is giving satisfactory results because the feedback grid currents in the synchronously rotating reference frame are following the references set for the current control loops. The active power transfer to the grid at iqref $=-5$ and id_ref $=0$ with DC link voltage of $300 \mathrm{~V}$.

- Active power and the reactive power can be controlled independently by setting the respective references for the active and reactive current control loops in the synchronously rotating reference frame with unity power factor. The THD analysis of the line current is shown in Figure 34, which gives satisfactory results.

- All this simulation results verify the effectiveness of the proposed control scheme. Also it can be concluded that the DC link capacitor voltages of a Neutral Point Clamped inverter can be balanced with the proposed space vector pulse width modulation technique without using any additional auxiliary circuits.

\section{REFERENCES}

[1] M. Galád, P. Špánik, "Design of Photovoltaic Solar Cell Model for Stand-alone Renewable System", 10th International Conference ELEKTRO 2014, pp. 285-288, 19-20 May, 2014, ISBN 978-1-4799-3720-2.

[2] Salama, A. Tabyaoui, M. Benchagra, "NPC Multilevel Photovoltaic Inverter with Nonlinear MPPT using Boost Converter", International Review of Automatic Control, vol. 10, no. 6, pp. 476-484, 2017.

[3] J. S. Lai and F. Z. Peng, "Multilevel Converters - A New Breed of Power Converters," IEEE Transactions on Industry Applications, "vol. 32, pp 509-517, June1996.

[4] C. D. Townsend, Y. Yu, G. Konstantinou, V. G. Agelidis, "Cascaded H-bridge multilevel PV topology for alleviation of per-phase power imbalances and reduction of second harmonic voltage ripple", IEEE Transactions on Power Electronics, vol. 31, no. 8, pp. 5574-5586, 2016.

[5] Y. Shashi Kumar and Rajesh Gupta, "Maximum Power Point Tracking of Multiple Photovoltaic Arrays", Students Conference on Engineering and Systems(SCES), pp;1-6,2012.

[6] W.C. Duesterhoeft, M.W. Schulzand E. Clarke, "Determination of Instantaneous Currents and Voltages by Means of Alpha, Beta, and Zero Components,"Transactions of the American Institute of Electrical Engineers, vol. 70, no. 2, p. 1248-1255, July1951.

[7] J. M. Carrasco, L. G. Franquelo, J. T. Bialasiewicz, E. Galvan, R. P Guisado, M.A. Prats, and N. Moreno-Alfonso, "Power-electronic systems for the grid integration of renewable energy sources: A survey," IEEE Transactions on Industrial Electronics, vol. 53, no. 4, pp. 1002-1016, 2006

[8] Yu. T. C., \& Lin. Y. C., “A Study on Maximum Power Point Tracking Algorithms for Photovoltaic Systems." Luangwa University of Science and Technology, Dept. of Electrical Engineering, 2010.
[9] Sedo J and Kascak S, "Control of Single-Phase Grid Connected Inverter System," in IEEE 2016 ELEKTRO, 2016.

[10] G. Walker, "Evaluating MPPT converter topologies using a MATLAB PV model," Journal off Electrical \& Electronics Engineering, Australia, vol. $21,2001$.

[11] Nicola Femia, Giovanni Spagnuolo, "Optimization of Perturb and Observe Maximum Power Point Tracking Method", IEEE transactions on Power Electronics Vol. 20, No. 4July 2005.

[12] O. Salama, A. Tabyaoui, M. Benchagra, "Analysis and comparison of Control on Power Converters in Photovoltaic Energy", Electrical and Information Technologies (ICEIT) IEEE International Conference on, pp. $1-8,2017$.

[13] D. Borgonovo, Modelling and Controlo d Three-Phase PWM Rectifier Using Park Transformation. Florianópolis, 2001. Dissertation of Master in Electrical Engineering - INEP, UFSC.

[14] C. Cecati, A. Dell'Aquila, M. Liserre. A novel three-phase single-stage distributed power inverter. IEEE Transactions on Power Electronics,Volume 19, Issue 5, Sept. 2004 Page(s):1226 - 1233.

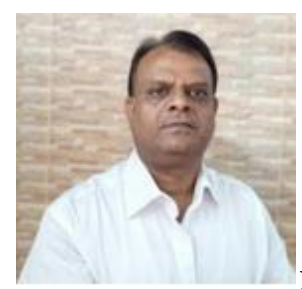

Dr. Umesh Kumar Sinha is a faculty in the Department of el ectrical engineering, National institute of Technology Jamshedpur. He has received the highest degree as Ph. D. in 2010 in the area of Solar energy. The research areas are the following: Solar and Renewable Energy Systems. Applications of Electromagnetic Fields, Power Electronics application in different drive systems, Modelling of Salt Gradient Solar Ponds for various applications, Development of Hybrid Systems. 